\title{
RWOPS abuse could cost, or even ruin, offenders
}

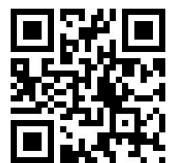

If a bid by state lawyers succeeds, the minority of state doctors proven to have sacrificed their legal/ ethical obligations to public sector patients in favor of private sector extra earnings could end up paying reparation - and some may even be financially crippled.

This emerged in the ongoing saga of Remunerated Work Outside the Public Service (RWOPS), which has played out most publicly in KwaZulu-Natal (KZN), Gauteng and the Free State recently. It also threw up a shaky truce between doctors and officials, following slurs on the medical profession and clumsy, sweeping clampdowns by some

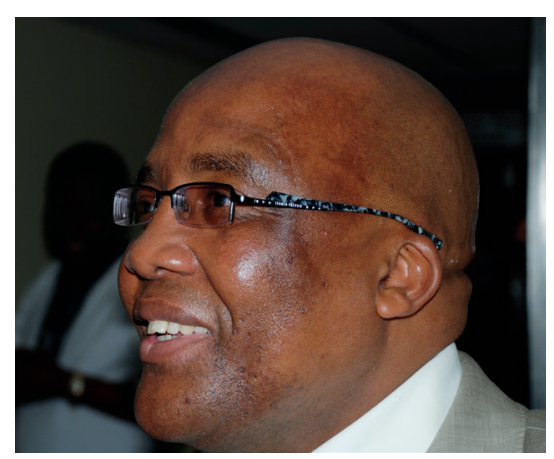

Minister of Health Dr Aaron Motsoaledi.

provincial health ministers. National Health Minister Dr Aaron Motsoaledi subsequently tried to mitigate these actions during his
Parliamentary budget speech, as well as in an interview with Izindaba. Izindaba learned that the truce has created the space for a renegotiated and more transparent RWOPS modus operandi, after the South African Medical Association (SAMA) and the deans of all eight medical schools met separately to try and hammer out tighter, more transparent proposals. The Committee of Deans' RWOPS report landed on Motsoaledi's desk on 1 July.

Motsoaledi told Izindaba that he is urgently trying to convene the National Health Council (consisting of himself and his nine provincial counterparts) to 'adopt, reject or modify' the report. The report will also be comprehensively interrogated by 
SAMA and the Health Professions Council of South Africa (HPCSA) before a 'joint decision' is taken. Motsoaledi said he had asked the deans to 'look at all sides of the issue. While he was predictably unwilling to share the deans' proposals, Izindaba did get insight into SAMA's proposal - which the association hopes will dovetail with the deans' work.

\section{KZN Health Department chief Dr Sibongile Zungu believes there should be 'an extra element of liability for those (consultants) who left their juniors unsupervised, thus causing patient harm'.}

\section{One possible RWOPS outcome}

At its most basic level the SAMA proposal, based on the Free State group practice model, involves eight hours of RWOPS per week in return for a peer-enforced guarantee that all clinics, theatre lists, ward rounds and on-call rosters are fully covered at all times and proper, detailed RWOPS applications are made. The clash between consultants and their provincial political and hospital bosses led to a Public Servants Association (PSA) court interdict in the Free State; a mudslinging battle royal in Gauteng, with SAMA calling for the resignation of provincial Health MEC Hope Papo; and a no-nonsense, hard-hitting legal probe in KZN. If the KZN probe proves legally feasible the other two provinces may emulate it. This will mean provinces may reclaim - from greater numbers of consultants - millions of rands in damages already paid out to patients who suffered adverse outcomes after being attended to by unsupervised junior doctors. Via medical aid payouts and identity (ID) numbers, KZN has identified some 300 of their 4000 doctors practising privately as possible targets of legal action.

KZN Health Department chief Dr Sibongile Zungu believes there should be 'an extra element of liability for those (consultants) who left their juniors unsupervised, thus causing patient harm' She revealed to Izindaba that she has $\mathrm{R} 1,1$ billion in medical negligence claims on her books, dating back 10 years (her current annual health budget is R29 billion). The most recently settled was a R6 million case involving a congenital abnormality, where the mother of a Downs syndrome child was not counselled for termination of pregnancy after having undergone an ultrasound examination.

Added Zungu, 'Generally, our legal team is trying to match what would have been the root causes of some of the cases where we have already considered liability, with the absences [of consultants].' While the state carries medical negligence insurance for its employees, her legal team is acting on the premise that financial liability should revert to the consultant if dereliction of duty (i.e. delegation to an inappropriatelyskilled or inexperienced colleague) can be shown. Zungu concedes that the terrain is fraught with obstacles, given that, among other things, 'we have to rely on the clinical guys for advice, so we may be damned if we do and damned if we don't!'

Provincial lawyers will have to gather evidence of times, dates and places where the RWOPS was conducted and match these with both the medical aid payouts and the public-sector adverse event. So far the RWOPS claims made on Discovery Health have proved the most helpful because of the company's advanced dataset, but the legal team is slowly breaking down national figures of other schemes into provincial statistics. Once doctors' ID numbers are matched with their practice numbers, says Zungu, 'we can aggregate the amount of money they were making at the expense of the public sector. You have to remember, we pay them full-time salaries.' She confirmed that most abusers in KZN are junior consultants, but also include general practitioners and dentists, adding that the probe embraced several professors 'whom the registrars go and assist with RWOPS'

\section{'Right now everybody is chasing} what is convenient or suitable for them. What exists is a national cabinet-ratified arrangement, [which is] not for any individual person or province to interpret as they wish.' - Motsoaledi.

Motsoaledi, while reiterating that 'criminality' would not be tolerated, was quick to downplay Zungu's initiative, saying she would have to subject herself to the National Health Council's decisions.

\section{Motsoaledi talks sweet and fast}

So far Izindaba is aware of six radiologists resigning at Chris Hani Baragwanath Hospital and at least eight Charlotte Maxeke anaesthestists leaving during the furious row between Papo, who labeled RWOPS abusers 'criminals and tsotsis', and SAMA's Public Sector Committee. National Health Director-General Precious Matsoto said Motsoaledi would meet with the medical deans and confirmed what several provincial MECs have told Izindaba: they are awaiting a firm policy directive from the National Department of Health before taking any disciplinary steps.

\section{Zungu confirmed that most abusers in KZN are junior consultants, but also GPs and dentists, adding that the probe embraced several professors 'whom the registrars go and assist with RWOPS'.}

In his budget speech, Motsoaledi said that the overwhelming majority of doctors in the public service are 'very decent, lawabiding, hard-working citizens who are deeply committed to their patients. It is only a few who are tarnishing the name of the profession. I am appealing that the events that unfolded over the media this week must not be misconstrued [as implying] that most doctors are involved in this practice and [that people must not] start regarding all doctors as some form of criminals. I want to repeat, the majority are very ethical citizens who understand their calling. The few individuals who are involved are not only punishing patients, they are also destroying medical training in the country because they leave medical students to their own devices. Even specialists in training are badly affected by being abandoned by people who are supposed to guide them in every step of their training.'

He added, to Izindaba, 'We have to get the laws and parameters correct. If these abusive doctors are in the majority, it means that we as a country are doomed - I don't want to believe that most of them want to destroy the healthcare system.

Motsoaledi said that criminal charges are 'unavoidable' for those who were 'caught redhanded, because we have their names and know their activities. We will also refer their names to the South African Revenue Service (SARS) to see if they are paying tax for the double income they are getting.'

Matsotso said RWOPS - which is, ironically, a retention and skills enhancement tool - applies to all public servants. The current healthcare probes would shortly be 
widened to embrace pharmacists and nurses. 'Those who committed fraud, we'll act against them, but it's also about management ... where were the CEOs and what did they do?'

\section{Private sector support}

In parliament, Motsoaledi warned the private sector, which is 'benefitting from this bad practice, that, in the long run, they also will suffer because the country will produce poorly-trained doctors.' He appealed to the private sector, which he described as 'hellbent on attracting public servants with lots and lots of perverse incentives,' to work with him rather than against him.

Netcare Hospital executives went to ground after narrowly averting a financial meltdown at their Pelonomi and Universitaslinked private hospitals, when Free State MEC Dr Benny Malakoane pulled the RWOPS plug on 90 public sector consultants. The consultants were bolstering the private hospitals in terms of a long-standing agreement with the province. Malakoane's unheralded edict, which banned all RWOPS work during official working hours, came just one month into his healthcare portfolio tenure, but was overturned via an interim court interdict brought by the PSA. Netcare began preparing their own court papers, but held back after a meeting with Malakoane in which they allayed some of his fears and agreed to help tighten up the monitoring of the existing contract.

Nationwide, an emerging theme seems to be a shifting of the onus for RWOPS monitoring and supervision to clinical chiefs. While CEO's and hospital managers will be held accountable, the principle of peer monitoring (group practice) and support in rooting out unethical and fraudulent activity by doctors themselves will be central to convincing government that RWOPS can remain in place and achieve its original goals.

Asked to comment on the Pelonomi and Universitas hospitals controversy, Motsoaledi said that 'even in its original form, RWOPS never encouraged people to go and do private work during normal [state] working hours. 'If that happens it must be by [national] agreement. We may have to modify RWOPS, but right now everybody is chasing what is convenient or suitable for them. What exists is a national cabinet-ratified arrangement, [which is] not for any individual person or province to interpret as they wish.'

\section{Roleplayers pitch in}

Professor Danie Marx, Head of Cardiology at the University of Free State and the
Universitas Hospital in Bloemfontein, said Malakoane cited certain secondary hospitals as the worst offenders. 'His main concern was patients not being looked after during working hours', he said. 'It was unacceptable to him and I told him we felt exactly the same way. He seemed happy with my explanation of how RWOPS was originally negotiated here, so long as we can guarantee 24-hour care for public sector patients.'

Dr Nick van Zyl, Head of Clinical Services at Universitas Hospital, also said Malakoane 'seemed happy' with revised RWOPS application forms and a tightened up internal policy, a process that Van Zyl began in April this year. He confirmed the province's earlier assertions that no RWOPS applications in the Free State have been approved in the past two years (the province contends that none were made). However, Van Zyl added that the negotiated agreement has been in place for so long that specialists have come to consider it part of their conditions of service. This point, and the lack of prior consultation, were central to the PSA's victory in their interim court interdict against Malakoane's sudden ban on RWOPS inside of working hours.

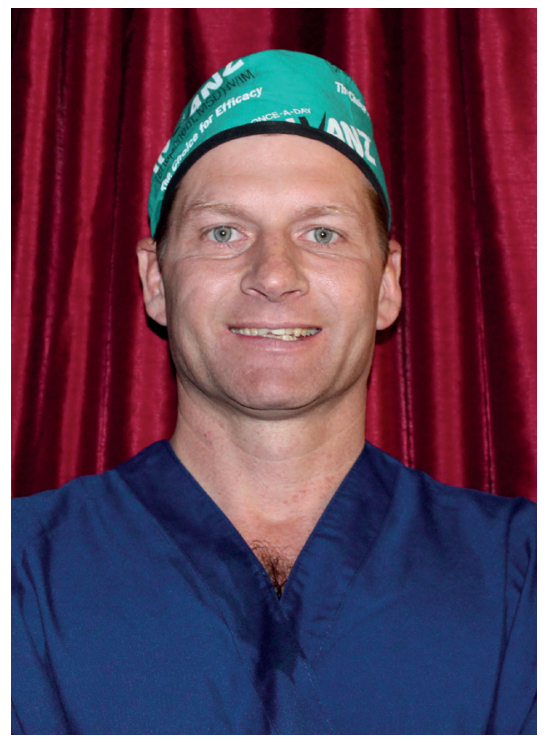

Dr Deon Menge, SAMA's Free State chairperson.

In $\mathrm{KZN}$, Zungu denied that her senior managers and staff are 'estranged' from their consultants. 'We've had ongoing quorums of heads of clinical departments and senior management, discussing this and various issues, including equipment.' Asked to describe the tone of the meetings, she admitted it was 'not the greatest at all. She said that among the doctors, there were 'those saying RWOPS can work and others totally against it.' She opined, 'We need a tool or mechanism to manage it and it's a peer thing, rather than an ordinary manager thing.'
Dr Deon Menge, SAMA's Free State representative and RWOPS issues national co-ordinator, said it is technically possible to claim for more than 16 hours overtime. (State doctors are paid for 40 hours a week, plus a flat rate for 16 hours overtime.) However, when some doctors tried this, the hospital chief unilaterally stopped it, citing budget constraints. 'We could clock in and out, but they couldn't afford it. Section Four (the relevant overtime regulation) is thus a foefie [trick] and hugely unfair.'

According to Professor Errol Holland, Chairperson of the South African Committee of Medical Deans and Dean of the Health Science Faculty at the Medical University of South Africa, 'a proper rational, constructive way', to ensure that the system operates optimally is urgently needed to address 'a problem of crisis proportions'. Each province seems to have a different approach to RWOPS, and a multi-stakeholder interim solution needs to be thrashed out, pending a review of the relevant legislation. 'One was hoping that with Occupation Specific Dispensation (OSD) one would remove the need for, particularly senior, staff to go out and supplement their salaries with RWOPS, but it's certainly not abated the problem,' he says. Holland described the current situation as 'untenable - it doesn't bode well for the profession, which has a much bigger mission: getting healthcare on track to serve our country's dire needs, particularly in the under-resourced population. We must keep the crisis of maternal and child mortality in mind and come together in a consultative forum to find an amicable approach.'

In a philosophical moment, Zungu mused: 'I'm just concerned with why we have to go and catch doctors. I worked at a time when we didn't count the hours of overtime ... perhaps we were stupid ... whether you were on call for two nights or 20 in a month, you got the same amount of money for your overtime. It was up to the camaraderie among peers as to who would work at Christmas and over public holidays - we'd decide that early in the year. There was no need for policing. What happened to that? It was professional behavior at its best - you understand your responsibilities and take them on. I was at a rural [district] hospital at the height of HIV in the 1990s, with sometimes just two doctors in the entire hospital and we did it all, without counting how often we'd be on call.'

\section{Chris Bateman}

chrisb@hmpg.co.za

S Afr Med J 2013;103(8):506-508.

DOI:10.1796/SAMJ.7235 